\title{
Hybrid Learning in Higher Education: The Potential of Teaching and Learning with Robot-Mediated Communication
}

\author{
Benjamin Gleason \\ Iowa State University \\ Christine Greenhow \\ Michigan State University
}

\begin{abstract}
Blended learning, which combines online and face-to-face pedagogy, is a fast-growing mode of instruction as universities strive for equitable and alternative pathways to course enrollment, retention, and educational attainment. However, challenges to successfully implementing blended instruction are that social presence, or students' ability to project their personal characteristics into the learning space, is reduced with potential negative effects on student engagement, persistence, and academic achievement. Instructors are experimenting with robotmediated communication (RMC) to address these challenges. Results from a study of RMC at a large public university suggest that it offers advantages over traditionally used videoconferencing, including affordances for fostering students' embodiment in the classroom, their feelings of belonging and trust, and their ability to contribute ideas in authentic ways.
\end{abstract}

Keywords: Blended (hybrid) learning, online learning, social presence, robots, embodiment

Gleason, B. \& Greenhow, C. (2017). Hybrid learning in higher education: The potential of teaching and learning with robot-mediated communication. Online Learning, 21(4), 159176. doi: 10.24059/olj.v21i4.1276

Hybrid Learning in Higher Education:

The Potential of Teaching and Learning with Robot-Mediated Communication

A synthesis of a decade of research (1996-2008) on online learning suggests that blended or hybrid learning, which combines face-to-face and online learning, is the most promising approach for K-12 and higher education (Means et al., 2010). Today, advances in technologies make possible new models for hybrid education. One such model features hybrid learners' synchronous online attendance of face-to-face courses with other students physically present on-campus, in the classroom (Roseth, Akcaoglu, \& Zellner, 2013). This model has the 
potential to enrich students' learning and make teaching and resource allocation more efficient, but poses several challenges. One is that students' ability to establish social presence - defined as learners' ability to project their personal characteristics into the learning environment - may be particularly challenging to establish in synchronous hybrid learning models. Social presence has been shown to be critical to course satisfaction, students' engagement, development of a community of inquiry and student learning outcomes. Low social presence leads to diminished learning outcomes. This study examines whether incorporating mobile social robotic systems (i.e., Double and Kubi robots) enhances social presence and embodiment within a synchronous hybrid course. Such research not only advances the knowledge base on the emerging field of social robotic telepresence but also provides needed insights about designs for new models of hybrid education. Next, we present our theoretical framework and review of relevant literature followed by our methods, presentation of results, discussion, and conclusion.

\section{Review of Related Literature}

Online learning is a fast-growing component of the field of education. However, research on the effectiveness of online learning approaches compared to traditional face-to-face instruction has shown mixed results (Means, Toyama, Murphy, Bakia, \& Jones, 2010). Today, many scholars agree that blended or hybrid learning, which combines face-to-face and online learning, is the most promising approach for increasing access to higher education and students' learning outcomes (Means et al., 2010). In fact, the number of universities utilizing blended courses is growing rapidly. Some estimate that between 80 and 90 percent of college and university courses will someday be hybrid (Young, 2002) and suggest that the amount of blended learning classrooms has increased 30 percent annually from 2001 to 2011 (Horn \& Staker, 2011).

In blended learning, portions of the course content are delivered online, typically through asynchronous instruction, supplementing face-to-face instruction in traditional classrooms. One model includes hybrid students attending face-to-face courses with students in brick-and-mortar classrooms. This synchronous hybrid education (in which online students learn through a technology-mediated "face-to-face" learning environment) promises enriched learning opportunities for the class as a whole by bringing together student perspectives from different educational backgrounds and contexts that may otherwise have remained separate (Bell, Sawaya, $\&$ Cain, 2014).

On the other hand, implementing synchronous hybrid learning poses challenges for students and instructors. One challenge is that social presence-an important aspect of a successful learning experience (Chickering \& Gamson, 1987) - is often more difficult for online students to form. Online students, especially, often complain about feeling disconnected from their instructor in the learning environment (Smith \& Taveras, 2005) or as interrupting interactions happening in the physical space of the classroom (Bell, Cain, Peterson, \& Cheng, 2016). Establishing social presence, or the ability of students to project their personal characteristics into the community of inquiry, thereby presenting themselves to other participants as "real people" (Garrison, Anderson, \& Archer, 2000, pp. 89) has proven to be very important for student satisfaction (Gunawardena \& Zittle, 1997), the development of a community of learners (Rourke, Anderson, Garrison, \& Archer, 2001), and students' learning (Richardson \& Swan, 2003). Richardson and Swan (2003) found that not only do students perceive learning benefits when they themselves are recognized as being "real" or "authentic," but also that students perceived learning benefits from being in the presence of others, 
acknowledging this presence as "an essential part" of the learning experience (p. 78-79). Richardson and Swan (2003) also reported that social presence could be developed or "cultured," aligning with what Garrison has proposed with his Community of Inquiry model (Akyol \& Garrison, 2008).

In a recent publication in Online Learning, Whiteside (2015) proposed a framework for social presence that suggested that class community and emotional connection are critical components of this construct. Other theoretical frameworks for social presence (Biocca, Harms, \& Burgoon, 2003) describe it as comprised of 1) co-presence, 2) psychological involvement, and 3) behavioral engagement. Co-presence involves students being aware of each other and feeling like they are in the same place. Psychological involvement exists when students are engaged in student-student and instructor-student interactions and there is mutual understanding. Behavioral engagement can involve "eye contact, nonverbal mirroring, turn taking, and so forth" (Biocca et al., 2003, p. 465). Some researchers have argued that social presence is a necessary precondition for learning to occur, especially collaborative and social learning (So \& Brush, 2008); others have argued that social presence is a by-product of an effective collaborative learning environment (Bower, Delgarno, Kennedy, Lee, \& Kenney, 2015). Taken together, these ideas suggest that high social presence is facilitated in learning environments where all students feel included, seen, heard, respected and "valued as people, not merely an image on a display or a body in a seat" (Bell et al, 2016, p. 20). Attending to social presence is important because (both online and offline) students' abilities to establish relationships with faculty and with other students have a direct and significant effect on their level of scholarly engagement and learning outcomes (Kuh, Cruce, Shoup, Kinzie, \& Gonyea, 2008).

Looking for ways to increase social presence within synchronous hybrid learning models, researchers today have begun to examine a new mobile technology: social robotic telepresence systems (SRTS) and their ability to foster social interaction between individuals (Kristoffersson, Coradeschi, \& Loutfi, 2013). SRTSs facilitate social interactions through an LCD screen, a web camera, microphone, and speakers - with the added functionalities of moving/steering the system to various locations - allowing communication between remote and local parties. SRTSs, such as the Double and Kubi robots, can be moved around by a remote user who is not situated at the robot site. (See Figure 1 for examples). 


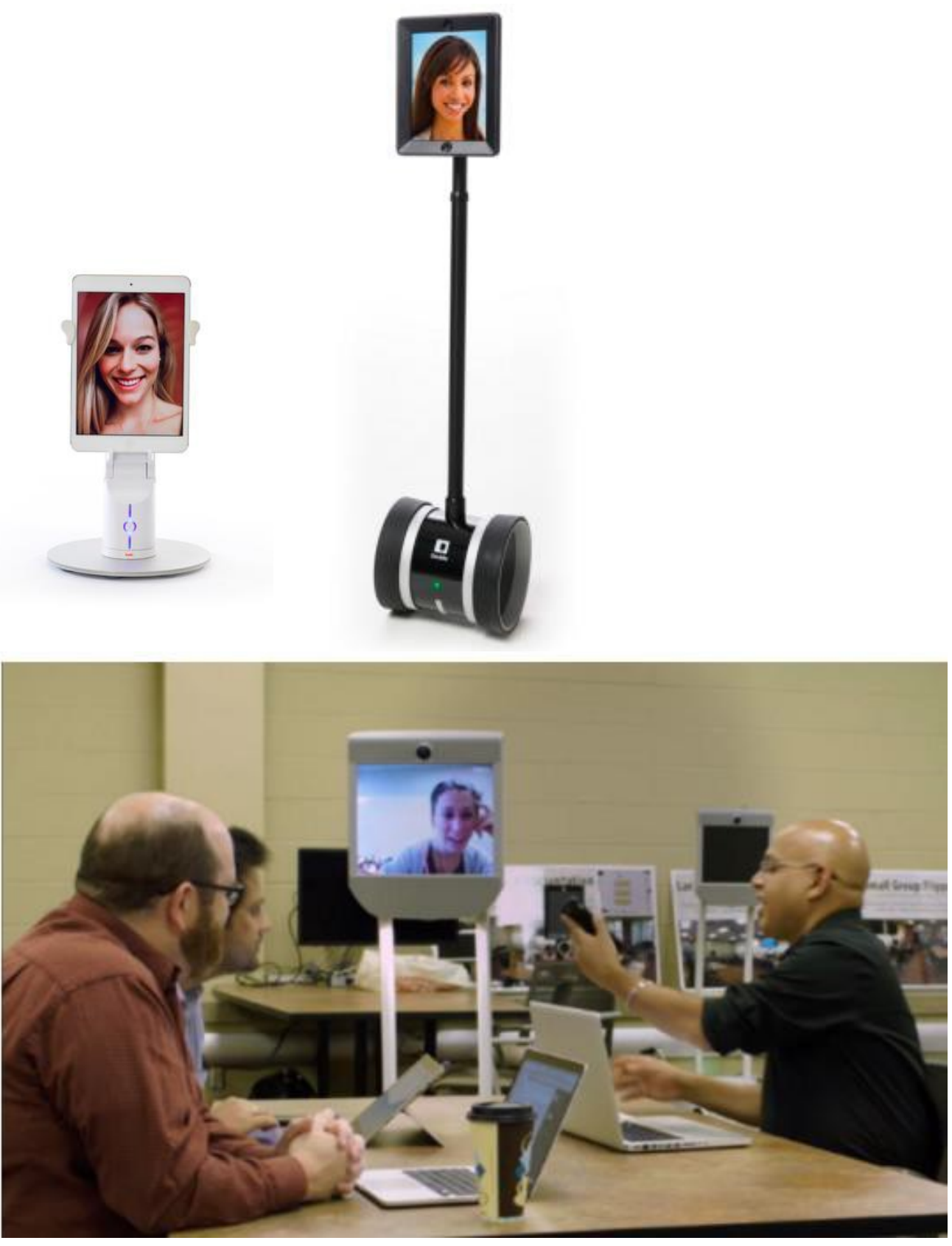

Figure 1. Social robotics telepresence systems used in hybrid doctoral education.

SRTSs offer users the unique potential for embodied communication which facilitates social presence. Embodiment may be experienced as the feeling of being within, having control over, and/or owning a given body (Kilteni, Groten, Slater, 2012), as the incorporation of an apparatus into body schema (Haans \& Isslestein, 2012), or as close connection between the virtual and physical body (Biocca, 2014). Embodiment contributes to social presence by facilitating the sense of being co-present (Biocca, Harms, \& Burgoon, 2003). This may occur when interaction partners are embodied physically (e.g., in robots; Lee, Jung, Kim, \& Kim, 2006) or virtually (e.g., in avatars; Bente, Rüggenberg, Krämer, \& Eschenburg, 2008). Further, embodied social presence 
has been found to enhance cognitive engagement and performance in shared activities (Mennecke, Triplett, Hassall, Conde, \& Heer, 2011), making it a particularly important topic in the examination of SRTSs within education settings. Buxton and colleagues have designed collaborative work spaces for remote workers, aiming to support the physical, social, and cognitive presence of workers through physical and virtual proximity (Sellen, Buxton, Arnott, 1992). Such systems may also become especially important in facilitating productive collaborations and a sense of "being there" for remote workers in today's hybrid work environments, including academia, as telecommuting has risen 79 percent between 2005 and 2012 and telecommuters, working alongside their face-to-face colleagues, constitute 30 percent of the U.S. workforce (Tugend, 2014). Moreover, we might expect this percentage to increase in the wake of studies that find today's employees have a strong desire for flexibility in where and when they work and report far higher engagement in their work when they have more choice (Schwartz \& Porath, 2014).

Currently, we are aware of only a handful of studies that have examined robot-mediated communication within higher education learning environments (Bell et al., 2016; Cain, Bell, \& Cheng, 2016; Tanaka, Nakanishi, \& Ishibguro, 2014). For instance, Tanaka et al. (2014) found social presence is facilitated through robot-mediated communication, specifically systems that "transmit bodily motions" (p. 109). Bell and colleagues (2016) studied the psychological, social, and emotional dimensions of effective online learning, especially for hybrid classes. In multiple iterations of the course, the researchers experimented with social robotic telepresence technologies and pedagogical imperatives, guided by student feedback. They found that one design solution to a pedagogical or technological problem often led to another, unintended issue. For example, the decision to position the video display at the front of the class led to "the realization that this approach tended to constrain the attentional capacities of the instructor" (p. 23); she could look at the face-to-face students in front of her, or turn around to address the online students. The authors noted how it was "surprisingly difficult" to consider the complex interplay of technologies, pedagogies, and psychological needs of face-to-face and online students (p. 23). While recent research has investigated the general principles of robot-mediated communication, this study investigated how the use of robot-mediated communication in higher education supported the learning environment.

\section{Methods}

Building on this gap in the educational research literature concerned with blended or hybrid learning environments mentioned above, we inquired: What is the nature of students' embodiment, social presence, and their classroom experience in robot-mediated learning?

\section{Data Sources}

We examined this question in an educational technology doctoral course at a large, public university in the Midwest US. The course included twelve online students enrolled in their first year of a hybrid doctoral program and one face-to-face student enrolled in her first year of an oncampus doctoral program. We obtained access to this group of students because the second author of this paper was also the course instructor. Students were introduced to the study by the first author, who was not at all involved in the course, and data analysis began at the end of the semester after the course was over. Eleven out of twelve possible students consented to participate in this study. 


\section{Data Collection}

Because our goal was to interpret and understand the nature of students' experiences with robot-mediated communication (compared to traditionally used video-conferencing), we collected data from a survey, focus groups, and students' written reflections. With each data source, we focused on students' 1) perceptions of social presence, 2) embodiment, and 3) transactional distance in terms of frequency of interaction, quality of interaction, sense of closeness/connectedness, and attention distribution. Ten of twelve online students and the one face-to-face student took a post-semester survey. Sample survey questions asked: "What impact did the use of robots (Kubi and Double) have on your ability to pay attention to the instructor" and "How would you rate the quality of the following interactions (face-to-face; in-person instructor to hybrid student; in-person student to hybrid; hybrid to hybrid)?"

Three focus groups of 3-4 students $(n=11)$ (Krueger \& Casey, 2014) were conducted at the end of the semester. Sample focus group questions included: "Whether you have used the robots or not, what do you see as the advantages of robots for whole class discussion? Disadvantages?" and "What do you feel are the major differences between using Zoom versus using robots to conduct a whole class discussion? Which do you prefer and why?" We also asked focus group questions that helped illuminate trends we were seeing in survey results, such as "In the survey, people largely agreed that they were able to express their ideas in the whole class discussion more than when they used Zoom for whole class discussion. Why do you think that might be?" and "In the survey, people largely agreed that they were able to build on the ideas that others expressed in the whole class discussion more than when they used Zoom for whole class discussion. Why do you think that might be?"

In addition, students reflected in writing near the beginning of the course, but after they had experienced the use of Zoom video-conferencing and robot-mediated communication to facilitate class discussions, and at the end of the course. We asked them to reflect on their experiences when they were in Zoom or robot form, or physically present (as in the case of one student), and when others were in these forms. Sample reflection questions included:

- How did the [insert robot or Zoom] help you to take part in whole group discussion, if at all?

- Specifically, what features or affordances, if any, did the [insert robot or Zoom] offer you that enhanced your ability to take part in the whole group discussion?

- Did using the [insert robot or Zoom] help you to interact with others (peers and/or instructor) in the whole group discussion? Please explain.

- Did using the [insert robot or Zoom] help your ability to collaborate in the whole group discussion? Please explain.

- Did using [insert robot or Zoom] help your ability to be present in the whole group discussion? Please explain.

- Were there any aspects to using the [insert robot or Zoom] in whole group discussion that you found challenged your ability to [insert interact, collaborate, be present] with your class (peers and/or instructors)?

In this paper, we draw from the focus group and beginning and end-of-semester written reflection data to describe themes that emerged in answer to our research question. 
Focus groups lasted forty-five minutes and were recorded and subsequently transcribed. Responses were then compiled and grouped by mediated form (RMC, Zoom, physically present). We engaged in thematic analysis (Glesne, 2016) and initially categorized the focus group data descriptively in terms of the reported advantages and disadvantages of each mediated form and their differences and preferences as expressed by students, related to social presence, embodiment, and transactional distance (Saldana, 2016). We also grouped students' responses to each of our focus group questions about the survey results and looked for themes in these responses. In addition to our a priori, etic categories related to our three focal topics, we allowed emic categorizations or codes to emerge based on what participants were telling us.

Reflection data were organized into a matrix with each row corresponding to each question asked and the columns corresponding to students' beginning and end-of-course responses (Miles $\&$ Huberman, 2013). Similar to our thematic analysis of the focus group data, we again looked for themes around our focal topic: the nature of students' experiences (i.e., social presence, embodiment, additional aspects of the classroom experience) with robot-mediated communication in light of traditionally used Zoom video-conferencing and physical presence. Next, we present a brief overview of the course's aims and the pedagogical strategies used related to the robotmediated communication in order to orient the reader to what implementing these technologies in this doctoral course actually looked like and the rationale behind our approach.

\section{Course Aims and Pedagogy}

In experimenting with robot technologies, the second author, also the course instructor, aimed to see if they helped increase students' experience of social presence, or social connection, and their sense of "being there" with their peers and instructor in the synchronous whole group class discussions compared to their experiences when video-conferencing software (e.g., Zoom) was used. Moreover, we were interested in all students' experiences - both the physically present student in our on-campus doctoral program and the online students in our hybrid doctoral program - and their sense of the interactions during synchronous class discussions. Facilitating effective discussions where all students are participating is essential to meeting course objectives; the course is framed on the assumption that participating in discussion brings with it several research-based benefits. These benefits include helping students explore a diversity of perspectives; increasing students' awareness of and tolerance for ambiguity or complexity; helping students recognize and investigate their assumptions; encouraging attentive, respectful listening; helping students become connected to a topic; affirming students as co-creators of knowledge; developing habits of collaborative learning; helping students develop skills of synthesis and integration; leading to transformation; and helping students connect their interests to the field (Brookfield \& Preskill, 2005).

Previously, in teaching this class, the instructor had used Zoom video-conferencing technology and wall-mounted displays to show all the online students' faces at once. Those physically present on campus in the class, seated around a table, looked up at the screen, not really knowing where to look (into the camera lens, at the student's face on screen) to best speak to online colleagues via Zoom. Similarly, the online students using Zoom viewed those sitting in the classroom from up on high and at a distance. We sought a technology that would help reduce that transactional distance and increase our senses of being there, together, engaged in discussion.

In partnership with our colleagues in the College of Education's Design Studio we sought to investigate and collect data on the relationship between students' social presence, embodiment, 
and their classroom experience in robot-mediated communication compared to videoconferencing communication in order to improve the overall quality of the synchronous class discussion.

Prior to the synchronous class meetings, online students and the face-to-face student corresponded in an online threaded discussion forum every other week. These discussions, focused around guided reading questions, took place asynchronously in the course website's discussion forum one week before our synchronous whole group class discussion. For the weeks that the class met synchronously, the face-to-face student, the instructor, and teaching assistant (who also provided technical support) attended class in a classroom on campus while the online students attended class using either traditional Zoom video-conferencing software or robot-mediated communication (i.e., Kubi or Double robots). During weeks in which the class met synchronously via Zoom, the online students logged into Zoom (www.msu.zoom.us) on their own computers and appeared as ten faces on a large screen that hung at the back of the classroom. The instructor, the on-campus students, and the teaching assistant sat in a semi-circle and faced this screen in order to facilitate a whole group class discussion.

During weeks where the class met synchronously using robot-mediated communication, the instructor, teaching assistant, and on-campus students again met in the classroom on campus while each online student logged into one of the ten robot devices positioned around the room. Such systems concentrate primarily on enabling social interactions via a video conferencing system with the added functionalities of a moving "head-screen" and steering the system to various locations. One such technology called a Kubi, pictured in the photo below (Figure 1) pairs an iPad with a desk-mounted swivel that is controlled by the online students remotely, so they can join inclass discussions like they were sitting at the table. Students using the Kubi have closer proximity to their face-to-face counterparts than when using wall-mounted displays. (As mentioned earlier, in prior iterations of this course, we used wall-mounted displays and Zoom video-conferencing technology to show all the students at once). Now, with the Kubi, students can be seen through a personal portal that they can control. The students (pictured in Figure 1) were two online students, tilting and panning their "head-screens" with the Kubi devices as they took part in class discussions. Kubis were positioned around a table in the classroom as if the online students were actually sitting with their on-campus peer and instructor.

In addition to the Kubi, the other robot technology used in this proseminar was called a Double, pictured in the photo (Figure 1). This technology takes the concept of autonomous telepresence a step further by letting users control a rolling motorized iPad mount that can be maneuvered around the room and steered from remote locations. A Bluetooth speaker paired to the iPad allows students to hear the student on the Double and his contributions to the class discussions. The Double robots were positioned around the room. Students who logged into the Double robot "drove" their mobile robot device to a position at the classroom table using arrows on their keyboard to steer the device remotely. Thus, SRTs like the Kubi and Double offer users the unique potential for embodied communication which has been shown to contribute to social presence. Drawing from the aforementioned literature, we expected that these robot technologies (Kubis and Doubles), with their added functionality for social interaction, would increase students' social presence and embodiment and reduce feelings of transactional distance in the synchronous, whole class discussion compared to when Zoom video-conferencing was used. To see in more detail what integrating this robot technology looks like in action and what students have to say about it, please see the short video https://youtu.be/oiW81rAIJCE 


\section{Results}

This section reports findings from our analysis of focus group transcripts and students' written reflections. We use pseudonyms instead of students' actual names. In answer to our research question: What is the nature of students' embodiment, social presence, and classroom experience in robot-mediated learning? two major themes emerged: in many ways students experienced a sense of embodiment and social presence through robot-mediated communication, but these were not without challenges compared to traditional video-conferencing.

\section{Embodiment in Hybrid Classrooms}

Focus group data suggested that all ten of the online students who participated in our study and experienced the class through RMC mentioned a general theme of physical presence or embodiment: a sense of being able to control a given body or see, hear, and be in a particular space. For instance, Lisa mentioned "embodied experience," and Chris said he felt like he had a "physical presence" in the classroom. For some students, the feeling of control in RMC-e.g., "being able to move the screen up" - afforded a "sense of freedom" that made the students "feel more physically and virtually present in the class." This experience was "more similar to being in the classroom [than video conferencing]." Some students noted that embodiment in RMC made it easier "to specify who [students were] addressing" and "to observe the nonverbals" of others. This created an awareness that "people can see what you're looking at," which one student noted "helps me pay attention." This was especially apparent during interactions with the professor, who was "clearly looking at you" and "addressing you directly" during RMC, which made one student "scared to death [she would] get caught dozing." Similarly, one student recalled a day when his robot's "head was broken." Unable to turn his robot's head-screen as he would normally do, he "felt disrespectful because [he] wasn't turning toward the speaker." The visual affordances of using the robots to see others facilitated learners' embodied experience. Stephanie, for instance, talked about being able "to see who you [other students] were." Moreover, three of the ten online students interviewed discussed the affordance of being able to move; Kevin said that the robot allowed him to get a "lay of the land," and Cai mentioned that "you can move" which she said felt "natural." Hannah mentioned that since the robots "could go," and "proximity is important," the robots helped her to "stay focused." The ability to control social interactions-e.g., "choose the proximity with the other" through moving the robot around the room-seemed to facilitate embodiment.

In their written reflections, students noted that robot-mediated communication helped them to communicate, interact, and participate with their peers, the instructor, and in small groups. Eleven of the twelve hybrid students noted that the affordance of having a "physical presence" in the room via the robots made them feel like they were in "an actual classroom." Hannah noted that positioning the robots at eye-level led them to feel part of a "group instead of outsiders looking in on a class" as is typical of the Zoom set-up. Here, it is important to reiterate that students in the class used two different kinds of robots: a stationary Kubi robot (left, in Figure 1), and a mobile Double robot (right, in Figure 1). Typically, Kubis were placed on a table-top, so that student learners in robot form were more or less at eye-level and could move their head-screen side to side and up and down. Though mobile, Double robots were often positioned in their charging stations around the perimeter of the room so they could roll up to the table when in active mode. In both forms, students mentioned that they appreciated being able to communicate with people in the room. 
This sense of connection between classmates in robot form was enabled by students being able to see, hear, and interact with each other-generally, being able to perceive the others. Significantly, students reported that the ability to move the Kubi robot to look at who was speaking supported increased communication and a sense of physical presence. One student noted that the ability to "control movement" (i.e., to direct the robot to look at a classmate or instructor by turning the robot's "head") "simulated an authentic experience." Another student noted that the "Double's capacity for movement gave me the sense of being in the classroom." A student's comment that "it's nice to have them [the robots] move around" (e.g., especially before class) was representative of the students' feelings about robot-mediated mobility.

One student mentioned that the Kubi robot helped her "as a distance learner to feel closer" to the students and faculty, especially when compared to video-mediated communication. Students reported that robot-mediated communication helped them develop embodiment with those people physically present (i.e., face-to-face student and the instructor), with one reporting that it "definitely helped me to interact" and another noting that the robot helped to facilitate "a more direct interface" with individuals.

In this study, the number of learners physically present in the classroom was limited to the instructor, the face-to-face student, and a teaching assistant who also served as the "technology navigator," assisting with technological issues. The face-to-face student, Abby, reported that she enjoyed "seeing them 'closer' to me than online," which she believed helped facilitate greater participation in class discussions. One reason Abby might have felt "closer" to the students in robot form, according to her written reflection, was due to their position in the classroom. Abby reported that the Kubi robots were positioned at eye-level, which was "similar to an actual classroom discussion." Thus, for Abby, having classmates in robot form was an advantage over video-mediated communication (i.e., videoconferencing software). Further, when the Kubi robots were positioned at "eye level," Abby noted that the mediated experience was similar to a traditional, face-to-face setting.

On the other hand, hybrid students described how robot-mediated communication, while an improvement over video-mediated communication, had some limitations. For example, students reported challenges perceiving other online students when they were in robot form, due to a narrow field of vision or being unable to hear or see students whose robots were positioned farther away from their own robot. In a written reflection, one hybrid student described the experience of this visual challenge as "each participant going through the class in their own individual tunnel." For this student, the narrow field of vision was perceived holistically as an embodied problem - that is, the inability to see a complete field of vision was felt by the whole body, and contributed to a sense of isolation.

Similarly, in focus groups, students reported obstacles to embodiment via RMC; five of the ten online students in our study mentioned "audio" or "hearing" as a challenge to using the robots. Stephanie explained, "It was much more difficult to hear and to see my peers." Lisa said, "The biggest one for me was volume," while Chris noted, "The audio was one disadvantage," noting that the audio was acceptable depending on his proximity to the other robot-speakers, but became "faint" the farther away he was positioned from robot-peers. Online students did not report any challenges in hearing their on-campus peer or their instructor or their teaching assistant when they were in robot form, and the on-campus student reported no challenges in seeing or hearing her online peers in robot form. Furthermore, three-quarters of the online students reported that the "visual" experience was challenging when using the robots for seeing other students in robot form. 
For instance, Michael commented, "It was really hard to see them [other robot-mediated peers]. It was hard to see their face." Cai reported, "Sometimes you're not clear. You know, the picture." Kevin said, "I couldn't see as well, especially if they [the robot-mediated peer] were turned." Abby explained, "I couldn't see everybody either and some people, yeah, would just keep their iPad facing one person so then you wouldn't really interact with them during the whole class discussion."

Two people mentioned the challenge of moving the robot or getting it in the ideal position. Chris explained, "The robot [the Double] was kinda slow and clunky to move." Hannah said, "Being close enough without being awkward and then not being so far away that you have problems like seeing and hearing and things like that." In their written reflections, students elaborated on the challenges associated with mobility in robot form, with some students commenting that a robot's mobile form could also diminish students' embodiment. Some students called the robots a distraction, with one reporting that he was "so focused on figuring out technology...that I was less focused" on course content. Another student reported that "navigating to optimal location precluded participating in discussion," while another critiqued the Double robot's tendency to "hover back and forth" while supposedly stationary. A fourth student described how the Double's capacity for movement led to concerns about violating classroom behavioral norms: "I didn't want to be rolling around and disrupting others." For some hybrid students, then, while the Double robot presented the affordance of mobility, in classroom practice this affordance was less useful, as it was confusing or distracting.

\section{Social Presence in Hybrid Classrooms}

Social presence - the ability of students to project their personal characteristics into the community of inquiry and feel co-located, seen, heard, and valued as "real" people-was experienced to varying degrees by the students in our study. Online students generally agreed that $\mathrm{RMC}$ facilitated their participation in the classroom community of inquiry and encouraged students to contribute ideas. The only face-to-face student, Abby, for instance, mentioned that this experience allowed her to feel a sense of "belonging" as a result of using the robots. Another student noted: "Using the robots helped me feel like I was there." One student remarked, "It felt like we were having a legitimate conversation" in RMC, which helped reinforce and support her own contributions. Another student felt that RMC encouraged her to "focus on what people are saying" and make connections to course content. Students mentioned that RMC helped them contribute ideas and develop a rich discussion, noting that the conversation was "germane" and "authentic." Aligned with Rae, Takayama, and Mutlu (2013), who found that people using a telepresence robot (like the one used in this study) were trusted more than those using a simple tablet, this study found that many students who used an SRTs (i.e., Kubi or Double) reported an increased sense of connection through RMC. For example, one student in the class reported that the use of the robots in class supported "our trust and our willingness to be open."

In their written reflections, students commented on how the robots' ability to support increased communication, interaction, and social presence in the class "felt natural," as one commented, "Seeing them [other students] closer provided a more comfortable atmosphere," while a second student noted that using the robots "felt more connected" than in a traditional class. Likewise, another student mentioned how "Being able to see them [peers] allowed me to stay focused on class discussion." Overall, hybrid students noted how robot-mediated communication supported interaction and the co-construction of ideas, with one student noting how robots "helped facilitate discussion and bounce ideas collaboratively off one another." Thus, 
hybrid students recognized the capacity of robots to support class discussion. Likewise, Abby, the face-to-face student, felt that the use of robot-mediated communication provided a "comfortable" environment for all students to participate and be physically present. Abby described how the physical layout of the classroom, in this case positioning the robots in a semi-circle, allowed her to connect with her classmates: "I could turn to my right or left and interact with a specific person...It helped create bonds." For the physically present student, the use of robots seems to facilitate the social presence of those students in robot form by first giving them the capacity for embodiment, and then facilitating connection, interaction, and collaboration.

At the same time, students recognized the relationship between the use of robots in a classroom and the pedagogical organization of the class. For example, students reported that "sitting in a circle" with the robots allows students to "look at each other," which seemed an appropriate pedagogical strategy for a discussion-based seminar. These findings demonstrate that for many students, the use of the robots for teaching and learning felt "natural" and helped them facilitate "legitimate conversation" but this was also a function of their arrangement in the classroom. For these students, RMC supported the development of rich discussion and coconstructed idea contribution.

On the other hand, several students observed that the robot-mediated audio was most effective when used to speak directly with those physically present (e.g., the instructor or face-toface student), and less so with their hybrid colleagues, especially those colleagues in robot form positioned farther away from their own robot form. One student described how the technical challenges presented by robot-mediated communication (i.e., lag-time between students; difficulty hearing or seeing other students) required the instructor to act as a "coordinator" who "pieced together other points" from students.

While many students appreciated the value of mobility via robot-mediated form in their written reflections (e.g., moving around the classroom, moving their head-screens, etc.), students also noted the challenges of teaching and learning in embodied, robotic form. For example, one student described how "fun" it was to use the Double (i.e., the rolling "mobile") robot, calling it an "added novelty," but he also wondered if he would choose it for himself. Along the same lines, one student noted that getting the attention of other classmates ("being perceived by them") was a challenge. For some students, the use of robots in class was somewhat of a distraction - with one noting that their embodied presence led them to lose focus ("My focus kept on going in and out").

\section{Discussion}

The purpose of this study was to investigate the nature of students' sense of embodiment and social presence when using robot-mediated communication in hybrid doctoral education and to explore the experience of teaching and learning in a robot-mediated classroom. In this study, we found that a majority of online students in a hybrid graduate course felt that the use of robots facilitated communication, interaction, and set the stage for possible collaboration and coconstruction of ideas. Students described how the use of robots enabled them to see, hear, and interact with those people physically present in the classroom (i.e., the instructor, teaching assistant, and face-to-face student) and their online peers, to varying degrees. This research found that the use of robots afforded a sense of physical presence for hybrid students; in a sense, the robots were online students' eyes and ears in the class, facilitating students' sense of actually "being" there. 
Results from this study indicate that the use of social robotics telepresence systems can enable hybrid students' sense of embodiment in a synchro-modal class, which may support their social presence, or sense of connection and belonging. This finding seems aligned with existing research in the field. The relationship between embodiment and social presence has been suggested in a number of different lines of research, including in Human-Computer Interaction (Tanaka et al., 2014), Design (Bell et al., 2016), Education (Bower et al., 2015; Whiteside, 2015), and others. So and Brush (2008) found a positive relationship between social presence and collaborative learning in a hybrid graduate course - that is, graduate students who felt connected to their peers reported a greater degree of motivation and investment in learning with (and from) their peers. In a study of seven different blended synchronous courses, Bower et al. (2015) proposed a number of critical components that support student learning, including technological, logistical, and pedagogical aspects. The authors also reported on design strategies that supported effective teaching and learning, including designing for active learning, matching technology to curricular requirements, distributing attention between face-to-face and online students, and establishing a learning community.

Bower et al. (2015) suggested that if these aspects were present in the hybrid course, class community and "co-presence" (i.e., a critical element of social presence) would occur as a result. For example, the authors reported that almost three-quarters of face-to-face students felt "copresent" with remote students, and that 60 percent of online students reported feeling "co-present" with face-to-face students. However, they also noted that the degree of co-presence "varied widely...depended on technology performance and human factors" (p. 13).

Similar to Bower et al. (2015), our study found that the benefits of robot-mediated communication are not evenly distributed among students enrolled in a hybrid course. Online students participating in robot-mediated communication appreciated the capacity to use robots to interact with those people physically present (i.e., the instructor and the face-to-face student) and described these interactions as contributing to their learning experience in the classroom. Without robot-mediated communication, online students reported that they felt disembodied; that is, their presence in the classroom was mediated through video, which felt superficial as if they were looking down (i.e., as if "on high") on the rest of the class. With robot-mediated communication, however, online students felt they had a presence in class, and could interact with those physically on campus. They could turn to face and address their interlocutor with the Kubi, or even move across the room to discuss with the Double robot.

This research aligns with findings from Cain et al. (2016), who reported that the use of social robotics telepresence systems in a hybrid course presented meaningful successes and noticeable challenges. For instance, the use of robots enabled online students to feel a sense of embodiment, or as Cain wrote, "providing a new and effective mode for online students to get individuated presence in a synchronous hybrid environment" (p. 173). The current study found that the use of mobile robots (e.g., Double robots) enabled hybrid students a greater degree of mobility, which in turn seemed to suggest increased possibilities for students to express autonomy in who they choose to learn from (and with).

However, collaboration with fellow online students via robot proved more challenging, as technical challenges made it difficult to see or hear peers. For instance, the limited range of vision meant that a robot could be seen by others, but often could not see others; it was almost as if students were wearing blinders. Similarly, the microphone on the robots picked up an excessive amount of background noise, making both proximal and distant conversations challenging to hear 
(Cain et al., 2016). The current study aligns with this earlier research that found that while social robotics telepresence systems can facilitate greater interaction and communication, these systems can also highlight "tensions" in current social and cultural practices.

This research draws attention to the ways that experienced teachers may reimagine pedagogical approaches in light of technological advances and possibilities (Mishra \& Koehler, 2006). For Bell and colleagues (2016; 2014; 2013), integrating cutting-edge technology into current pedagogical practices was made more successful by following a number of critical design principles. First, technology is dynamic, and the function, flow, and format of current technological systems is likely to evolve, challenging teachers, researchers, students, and instructional designers to accept more temporary solutions to enduring sociotechnical problems.

Second, Bell and colleagues found that a faculty member's "risk tolerance" goes a long way toward handling the numerous technological challenges that are bound to arise, even when faculty and instructors are impeccably prepared. Third, the authors encouraged teachers, researchers, instructional designers, and others to continue to collect and interpret data from technology-mediated courses; this strategy aims to create a feedback loop where student data informs future iterations of technology, pedagogy, and course groupings.

The collection and interpretation of student data may urge educators to consider how technology can support pedagogical experimentation and innovation. In a written reflection, one hybrid student advocated for "making use of the mobility of Doubles for learning," which suggests that hybrid teaching with embodied robots requires significant shifts from traditional, face-to-face teaching methods. In this case, instructors are advised to recognize the affordances of emerging technologies, such as mobilities, and consider the ways that student mobility might reorganize teaching and learning. Almost a decade ago, responding to global changes in networked society, and the resulting changes in daily life as a result, Leander, Philips, and Taylor (2010) wrote of the ways that considering learning as mobilities may spur essential new questions for the field of education: "How do people (on the move) build qualitatively distinct relations with different learning 'environments'?" (2010, p. 331). We can take Leander's question metaphorically to inquire about the possibilities that student mobilities via robot-mediated forms may have on challenging current models of hybrid (blended) or online education. How might robot-mediated classes suggest new visions for the dimensions, scope, and feeling of hybrid education? What happens when learner mobility is imagined as a feature (rather than an outlier) of learning? How might graduate education be different if classes are organized around dynamic movement rather than static sitting? These are just some of the questions our study raises that point the way toward future research in hybrid education with social robotic telepresence systems.

\section{Limitations}

Ours was a small-scale qualitative study to explore the nature of students' embodiment, social presence, and their classroom experience in robot-mediated learning. A strength of our methods was that they provide detailed descriptions of students' perceptions in a range of mediated forms (RMC, video-conferencing, physically present). A weakness, however, is that we did not capture observational data which could have been used to confirm or disconfirm what students were telling us. Moreover, we collected data from only one group of students in a graduate seminar where class discussion is a key pedagogical strategy. Collecting data related to our research questions from a variety of students (e.g., undergraduates) in hybrid learning contexts (e.g., larger 
classes with a more balanced mix of online-to-on campus students and that use different pedagogical strategies such as lecture) would strengthen the research base.

As faculty, instructional designers, and others involved in online learning consider this approach in similar educational contexts, we would like to point out a few limitations to using robot-mediated communication in small seminar courses. First, the audio quality of the Double technology is not as good as is that of the Kubis. This is especially an issue when online students on the Kubis cannot hear the student on the Double who is on the other side of the table. Second, the Kubis and Doubles are limited in their ability to zoom in and zoom out, which is an issue when the robots are situated too close to each other. Third, the on-campus student in this study felt that the class discussion was improved when her peers were in robot form, but that her interaction with the instructor suffered since facilitating a discussion with the robots took more time and attention from the instructor than did her merely looking up at a Zoom video-conferencing screen. Fourth, this approach works well in small seminars where interactive discussion is a key part of the pedagogical strategy, and there are roughly equal numbers of online and on campus students. Students and instructors must also be willing to try out new technology, knowing there can be technological and pedagogical issues along the way. This approach may be suited to larger classes where there are small numbers of online students; however, if lecture is the primary pedagogical strategy, Zoom video-conferencing will likely be preferred due to its screen-sharing capability, which facilitates slide-sharing during lectures and instructor control.

\section{Conclusion}

As colleges and universities continue to find ways to increase their enrollments such as offering expanded and alternative pathways to education for all students, especially nontraditional or under-represented students, hybrid or blended learning programs are a promising solution. This first-of-its kind study of robot-mediated blended learning suggests that RMC can offers several advantages over traditionally used videoconferencing systems for fostering social presence and embodiment in doctoral education. Additional design studies are needed to examine the interaction of hybrid pedagogy and robot technology over a longer period than a one-semester course, with additional groups of students (e.g., undergraduates), and connected to student learning outcomes. 


\section{References}

Akyol, Z., \& Garrison, D. R. (2008). The development of a community of inquiry over time in an online course: Understanding the progression and integration of social, cognitive and teaching presence. Journal of Asynchronous Learning Networks, 12, 3-22.

Bell, J., Sawaya, S., \& Cain, W. (2014). Synchromodal classes: Designing for shared learning experiences between face-to-face and online students. International Journal of Designs for learning, 5(1).

Bell, J., Cain, W., Peterson, A., \& Cheng, C. (2016). From 2D to Kubi to Doubles: Designs for student telepresence in synchronous hybrid classrooms. International Journal of Designs for Learning, 7(3).

Bente, G., Rüggenberg, S., Krämer, N. C., \& Eschenburg, F. (2008). Avatar-mediated networking: Increasing social presence and interpersonal trust in net-based Collaborations. Human Communication Research, 34(2), 287-318.

Biocca, F. (2014). Connected to My Avatar. In Social Computing and Social Media (pp. 421429). Springer International Publishing.

Biocca, F., Harms, C., \& Burgoon, J. K. (2003). Toward a more robust theory and measure of social presence: Review and suggested criteria. Presence: Teleoperators and Virtual Environments, 12(5), 456-480.

Bower, M., Dalgarno, B., Kennedy, G. E., Lee, M. J., \& Kenney, J. (2015). Design and implementation factors in blended synchronous learning environments: Outcomes from a cross-case analysis. Computers \& Education, 86, 1-17.

Brookfield, S. D. \& Preskill, S. (2005). Discussion as a way of teaching: Tools and techniques for democratic classrooms (2nd ed). New York: Wiley.

Cain, W., Bell, J., \& Cheng, C. (2016, July). Implementing Robotic Telepresence in a Synchronous Hybrid Course. In Advanced Learning Technologies (ICALT), 2016 IEEE 16th International Conference on (pp. 171-175). IEEE.

Chickering, A. W., \& Gamson, Z. (1987). Seven principles for good practice in undergraduate education. AAHE Bulletin, 40(7), 3-7.

Garrison, D. R., Anderson, T., \& Archer, W. (2000) Critical inquiry in a text-based environment: Computer conferencing in higher education. The Internet and Higher Education, 2(2-3), 87-105.

Glesne, C. (2016). In Becoming qualitative researchers (5th ed.). New York, NY: Pearson.

Gunawardena, C. N. (1995). Social presence theory and implications for interaction and collaborative learning in computer conferences. International Journal of Educational Telecommunications, 1(2/3), 147-166.

Gunawardena, C. N., \& Zittle, F. J. (1997). Social presence as a predictor of satisfaction within a computer-mediated conferencing environment. The American Journal of Distance Education, 11(3), 8-26. 
Haans, A., \& IJsselsteijn, W. A. (2012). Embodiment and telepresence: Toward a comprehensive theoretical framework. Interacting with Computers, 24(4), 211-218.

Horn, M.B. \& Staker, H. (2011). The rise of K-12 blended learning. New York, NY: Innosight Institute.

Kilteni, K., Groten, R., \& Slater, M. (2012). The sense of embodiment in virtual reality. Presence: Teleoperators and Virtual Environments, 21(4), 373-387.

Kristoffersson, A., Coradeschi, S., \& Loutfi, A. (2013). A review of mobile robotic telepresence. Advances in Human-Computer Interaction, 2013, 3.

Krueger, R. A., \& Casey, M. A. (2014). Focus groups: A practical guide for applied research (5th ed.). Thousand Oaks, CA: Sage.

Kuh, G.D. (2002). The National Survey of Student Engagement: Conceptual Framework and Overview of Psychometric Properties. Center for Postsecondary Research, Indiana University, Bloomington. Retrieved from http://nsse.iub.edu/pdf/psychometric_framework_2002.pdf

Kuh, G.D., Cruce T.M., Shoup R., Kinzie J. \& Gonyea R.M. (2008). Unmasking the effects of student engagement on first-year college grades and persistence. Journal of Higher Education 79, 540-563.

Leander, K. M., Phillips, N. C., \& Taylor, K. H. (2010). The changing social spaces of learning: Mapping new mobilities. Review of Research in Education, 34(1), 329-394.

Lee, K. M., Jung, Y., Kim, J., \& Kim, S. R. (2006). Are physically embodied social agents better than disembodied social agents?: The effects of physical embodiment, tactile interaction, and people's loneliness in human-robot interaction. International Journal of Human-Computer Studies, 64(10), 962-973.

Means, B., Toyama, Y., Murphy, R., Bakia, M., \& Jones., K. (2010) Evaluation of evidencebased practices in online learning: A meta-analysis and review of online learning studies. U.S. Department of Education.

Mennecke, B. E., Triplett, J. L., Hassall, L. M., Conde, Z. J., \& Heer, R. (2011). An examination of a theory of embodied social presence in virtual worlds. Decision Sciences, 42(2), 413- 450.

Miles, M. B., \& Huberman, A. M. (2013). Qualitative data analysis: An expanded sourcebook (3rd ed.). Thousand Oaks, CA: Sage.

Mishra, P., \& Koehler, M. J. (2006). Technological pedagogical content knowledge: framework for teacher knowledge. Teachers College Record, 108(6), 1017.

Rae, I., Takayama, L., \& Mutlu, B. (2013, March). The influence of height in robot-mediated communication. In Proceedings of the 8th ACM/IEEE international conference on Human-robot interaction (pp. 1-8). IEEE Press.

Richardson, J. C., \& Swan, K. (2003). Examining social presence in online courses in relation to students' perceived learning and satisfaction. Journal of Asynchronous Learning Networks, 7(1), 68-88. 
Roseth, C., Akcaoglu, M. \& Zellner, A. (2013). Blending synchronous face-to-face and computer supported cooperative learning in a hybrid doctoral seminar. Techtrends, 57 (3), 54-59.

Rourke, L., Anderson, T., Garrison, D. R., \& Archer, W. (2001). Assessing social presence in asynchronous text-based computer conferencing. Journal of Distance Education, 14(2). Retrieved from http://cade.athabascau.ca/vol14.2/rourke_et_al.html

Rovai, A. P. (2002). Building a sense of community at a distance. International Review of Research in Open and Distance Learning, 3(1). Retrieved from http://www.irrodl.org/ index.php/irrodl/article/view/79/153

Saldaña, J. (2016). The coding manual for qualitative researchers (3rd ed.). Thousand Oaks, CA: Sage.

Schwartz, T., \& Porath, C. (2014). The power of meeting your employees' needs. Harvard Business Review, 26(6), 442-457.

Sellen, A., Buxton, B., \& Arnott, J. (1992, June). Using spatial cues to improve videoconferencing. In Proceedings of the SIGCHI conference on Human factors in computing systems (pp. 651-652). ACM.

Smith, G. G., \& Taveras, M. (2005, January). The missing instructor: Does e-learning promote absenteeism? eLearn Magazine, 1. Retrieved from http://www.elearnmag.org/subpage.cfm?section=tutorials\&article=18-1

So, H.-Y., \& Brush, T. (2008). Students perceptions of collaborative learning, social presence, and satisfaction in blended learning environment: Relationships and critical factors. Computers \& Education, 51(1), 318-336.

Swan, K., Shea, P., Richardson, J., Ice, P., Garrison, D. R., Cleveland-Innes, M., \& Arbaugh, J. B. (2008). Validating a measurement tool of presence in online communities of inquiry. E-Mentor, 2(24), 1-12. http://online.purdue.edu/sites/purdue/files/Validatinga-Measurement-Tool-of-Presence-in-Online-Communities-of-Inquiry.pdf

Tallent-Runnels, M. K., Thomas, J. A., Lan, W. Y., Cooper, S., Ahern, T. C., Shaw, S. M., \& Liu, X. (2006). Teaching courses online: A review of the research. Review of Educational Research. 76(1), 93-135.

Tanaka, K., Nakanishi, H., \& Ishiguro, H. (2014, September). Comparing video, avatar, and robot mediated communication: pros and cons of embodiment. In International Conference on Collaboration Technologies (pp. 96-110). Springer.

Tugend, A. (2014, March 7). It's unclearly defined, but telecommuting is fast on the rise. The New York Times. Retrieved from http://www.nytimes.com

Whiteside, A. L. (2015). Introducing the social presence model to explore online and blended learning experiences. Online Learning, 19(2).

Young, J.R. (2002). "Hybrid" teaching seeks to end the divide between traditional and online instruction. Chronicle of Higher Education, 48(28), A33-34. 